\section{A. ARS BILDUMA

https://doi.org/10.1387/ars-bilduma.21985 BIBLID [(2021), 11; 69-81]

Recibido: 01/04/2020 Aceptado: 23/07/2020

\section{MARCOS ANDRÉS SALA IVARS}

Universidad Complutense de Madrid

Departamento de Historia del Arte Facultad de Geografía e Historia

C/ Profesor Aranguren, s/n

28040 Madrid (Madrid)

salaivars@hotmail.com

https://orcid.org/0000-0002-2660-1360

Secretario del Grupo de Investigación Asia (GIA).

\title{
ESTUDIO Y CATALOGACIÓN DE LAS COLECCIONES PÚBLICAS DE SABLES JAPONESES EN EL PAÍS VASCO
}

\section{STUDY AND CATALOGUE OF THE PUBLIC COLLECTIONS OF JAPANESE SWORDS AT THE BASQUE COUNTRY}

スペイン・バスク地方における日本刀の研究と目録

RESUMEN

Desde los primeros contactos entre España y Japón, una de las facetas que más ha llamado la atención del país del sol naciente es todo lo relacionado con la nobleza guerrera o clase samurái. En este artículo analizaremos los sables japoneses presentes en las colecciones públicas del País Vasco. Esta investigación científica supone un estudio pionero y razonado sobre estas piezas, basándonos en las más novedosas publicaciones del campo de la armamentística japonesa, incorporando traducciones inéditas hasta el momento.

PALABRAS CLAVE

Japón; sables; colecciones; nihontō; tsuba.
ABSTRACT

From the first contacts between Spain and Japan, one of the facets that has most attracted the attention of the land of the rising sun is everything related to the warrior nobility or samurai class. In this article we will analyze the Japanese swords present in the public collections of the Basque Country. This scientific investigation supposes a pioneering and reasoned study on these pieces, based on the most recent publications in the field of Japanese weapons, incorporating previously unpublished translations.

\section{KEYWORDS}

Japan; swords; collections; nihontō; tsuba.
概要

スペインと日本が交流を始めて以来、日 出ずる国の最も注目を集めた側面は武 士、あるいは侍階級にまつわる諸々のこ とである。

当論考では、バスク地方にあるパブリッ クコレクションの日本刀について分析す る。この研究は、日本の武器に関する最 新の刊行物をもとに、今まで未刊行だっ た翻訳も取り入れ、熟考した先駆的なも のである。

キーワード

日本、サーベル、コレクション、日本刀、鐔 


\section{ESTADO DE LA CUESTIÓN DE LAS COLECCIONES DE ARMAMENTO JAPONÉS EN ESPAÑA}

Las relaciones entre España y Japón se remontan a 1549 con la llegada de San Francisco Javier a costas japonesas. Sin embargo, la debida apreciación de las armas japonesas como objeto de arte no sucedió hasta muchos siglos después, como atestiguan las piezas de las colecciones españolas ${ }^{1}$. Salvo contadas excepciones, relativas a regalos institucionales de embajadores y visitantes japoneses, observaremos que el grueso de obras de calidad que se conservan en colecciones españolas corresponde a donaciones de coleccionistas particulares de principios-mediados del siglo XX. En este caso nos estamos refiriendo a compradores que, sin tener pleno conocimiento de la historia del arte del armamento nipón, huyen de las piezas de baja calidad presentes en lugares como los muelles de Yokohama ${ }^{2}$, para buscar en tiendas especializadas y anticuarios. Durante la era Meiji (1868-1912) y parte de la era Taishō (1912-1926), el mercado del arte japonés se extendió por Europa gracias a Exposiciones Universales y subastas de arte. En relación con los coleccionistas españoles, Francia tuvo un papel predominante como catalizador de piezas de arte y armamento japonés.

Llegados a mediados del siglo XX, varias colecciones privadas en España se están iniciando o afianzando. En estos casos los coleccionistas ya no buscan objetos de estudio antropológico o exóticos suvenires, sino obras de arte dentro de la armamentística japonesa. Estamos hablando de personas conocedoras del arte japonés, de su historia militar y que se han aproximado a trabajos historiográficos de armamento japonés, tanto en el idioma nipón, como en algunos escasos ejemplares en inglés o francés. Algunos de estos coleccionistas acabaron legando parte o la totalidad de las obras adquiridas a museos y colecciones públicas españolas, otros preferirán mantenerlas quedando al cuidado y disposición de sus descendientes y familiares. El fenómeno del "coleccionista entendido en armamento japonés" ${ }^{3}$ ha logrado que determinados museos españoles se conviertan en excelentes escaparates de algunas de las más exquisitas obras de arte bélico nipón.

1 SALA IVARS, M. A.: "Los sables japoneses y sus complementos: objetos de deseo de nuestros coleccionistas/compradores". Revista de Museología. № 65. Colecciones Asiáticas en España, 2016. pp. 54-66.

2 Con la llegada de la nueva era Meiji (1868-1912), el comercio de Japón con el exterior se reactivó, y las potencias extranjeras comenzaron a comprar grandes cantidades de suvenires y objetos artísticos de baja calidad, puesto que sólo les interesaba el origen exótico del mismo. En este punto, los almacenes de la ciudad portuaria de Yokohama jugaron un importante papel de productores y exportadores de este tipo de objetos.
Pese a que estas "nuevas" colecciones superan en mucho a la calidad de las piezas adquiridas antes del siglo XX, no son homogéneas en cuanto a las obras que las componen. Determinados coleccionistas fascinados por la faceta militar del armamento japonés optarán por adquirir sables y puñales completos (tachi, katana, wakizashi y tantō $)^{4}$. En estas colecciones es muy fácil encontrar hojas de buenos forjadores montadas en koshirae ${ }^{5}$ de baja calidad y viceversa. También tenemos constancia en España de otro tipo de coleccionistas, interesados casi exclusivamente en la faceta artística de las piezas que componen la montura del sable japonés. Debido al pequeño formato de estas piezas (no suelen superar los $10 \mathrm{~cm}$ en ninguno de los casos), se hace más fácil transportarlas y almacenarlas. Sin embargo, esto también ha hecho que algunas piezas se pierdan quedando algunos conjuntos incompletos. La valoración de estas piezas metálicas que conforman las monturas de los sables japoneses (tsuba, fuchi, kashira, menuki, kozuka y kōgai) ${ }^{6}$ no dependía de conocimientos técnicos sobre la forja del sable japonés, pudiendo admirarlas por su fino trabajo de orfebrería.

Uno de los puntos importantes dentro de la catalogación de estas armas japonesas en las colecciones españolas es el apartado dedicado a la procedencia de cada pieza. Los verdaderos orígenes japoneses de las distintas piezas, muy excepcionalmente se ven reflejados en los documentos que conservamos. Por ello, es sumamente importante investigar la historia

3 SALA IVARS, M. A.: "Francisco López López, coleccionista y erudito del sable japonés" en LÓPEZ, P, ELIZONDO. M. J.: El Sable Japonés: Manual de Coleccionista. Editorial Alas. Barcelona, 2016, pp.11-15 4 Diferentes tipos de armas blancas japonesas. Tachi es una palabra que se puede usar indistintament para cualquier tipología de sable largo japonés, sin embargo, su utilización como tipología propia se suele circunscribir a las tipologías de sables con una curvatura pronunciada, surgidos y utilizados entre los siglos X y XIV, así como sus derivados que siguieron utilizándose de modo decorativo/protocolario en los siglos siguientes, portándose siempre con el filo hacia abajo. La palabra katona también se suele

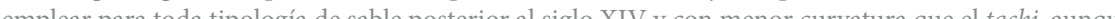
se suele circunscrib sobre los sade ban con el filo hacia arriba. Dicese de wakizashi, aquel sable corto que se introduce en el cinto con el filo hacia arriba y que hace compañía a la katana. Los tantō se refieren a los puñales japoneses, pudiendo haber diversas tipologías amparadas bajo esta denominación.

5 Denominación de la montura o "vestimenta" del sable japonés, en tanto que la palabra koshiraeru significa: vestir.

6 Diferentes partes de la montura de sable japonés que los coleccionistas podían comprar de manera independiente al resto del sable y establecer colecciones especializadas en varias o sólo una de estas piezas. Tuba es ol gares Tsuba es grar una pieza decorativa ubicada en la empunadura del sable, y los dos ultimos son complementos que s introducían a través de orificios en la guarda, quedando recogidos en la vaina del sable. Kögai o pasador de pelo y conjunto kogatana-kozuka, que es un conjunto de pequeña empuñadura con un estilete. 
de cada museo/colección con sus coleccionistas/mecenas, pudiendo establecer relaciones con posibles compradores o donantes. Sin embargo, nuestra fuente principal sigue siendo la propia naturaleza de las piezas, que si bien no puede hablarnos sobre los datos de venta o adquisición de estas obras de arte, en ocasiones si puede ofrecer información sobre la procedencia geográfica del taller donde han sido fabricadas.

Es por este motivo que no debemos desvincular las piezas de sus colecciones, estudiándolas en su conjunto museográfico, de forma que podamos obtener cuanta mayor información posible de todas las fuentes a nuestro alcance. Estas fuentes, retroalimentarán las lagunas existentes entre la propia historia de la colección y la naturaleza y origen de las piezas. En cada uno de los casos el esquema a seguir será presentar el museo o institución que alberga los sables japoneses o las partes de su montura, seguido de un estudio de la colección, prestando especial interés a la figura del coleccionista (de haberlo/conocerlo). Por último, ofreceremos un listado de las piezas estudiadas en cada una de las instituciones, estableciendo un criterio de orden de las colecciones de carácter alfabético.

\section{LA COLECCIÓN DE ARMAS JAPONESAS DEL MUSEO ARMERÍA DE ÁLAVA - ARABAKO ARMA MUSEOA (VITORIA-GASTEIZ)}

En los años 60 la Diputación Foral de Álava recibió una numerosa colección de armas, armaduras y otros objetos de índole militar pertenecientes a Felix Alfaro Founier. Con el fin de dar salida a estas obras, de forma que todos puedan admirarlas, se creó en 1966 el Museo Armería de Álava. La primera sede del Museo será el Palacio de los Gobeo-Guevara San Juan, una casa armería del siglo XVI en pleno centro de Vitoria que había sido restaurada ${ }^{7}$. Con el paso de los años la colección irá en aumento gracias a nuevas donaciones, haciendo que el espacio expositivo se quede pequeño. La adquisición del Palacio de Ajuria Enea por la Diputación Foral de Álava favoreció el que se habilitaran las edificaciones anexas como Museo de Armería. El nuevo espacio museográfico abrió sus puertas en 1975, exhibiendo armas y armaduras desde la Prehistoria hasta la actualidad, hoy se puede visitar en el Paseo de Fray Francisco 3, Vitoria.

VV.AA. Museo Provincial del Álava. Diputación Foral de Álava. Consejo de Cultura. Vitoria, 1967.

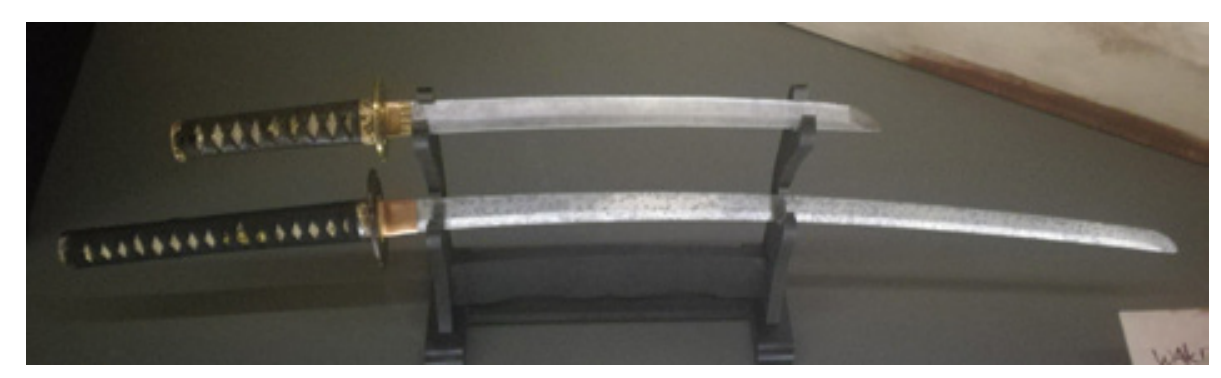

Fig. 1: Dos de los sables de los siglos XVII-XIX. Museo Armería de Álava, Vitoria-Gasteiz

Félix Alfaro Fournier, nieto del famoso empresario vitoriano del naipe Heraclio Fournier se hace cargo de la fábrica de su abuelo en 1916. Félix se convierte en un gran mecenas de las artes y el deporte en Vitoria. Pese a su pasión por las Bellas artes, su afición de coleccionista se centra en la empresa familiar de naipes y en las armas. En el primer caso logrará hacerse con naipes de todo el mundo y de todas las épocas, fundando el Museo de Naipes de Vitoria ${ }^{8}$. Gracias a su afición por la industria de las artes bélicas reunirá numerosas piezas de diferentes partes de España y del globo terráqueo, fundando el Museo Armería de Álava. Dentro de las piezas que comprenden su colección hay lugar también para armas japonesas, que son el principal objeto de nuestro estudio. Cuatro sables largos o katana, ninguno de ellos firmados. Aparte, también encontramos una katana de los siglos XVIII-XIX, montada con hiramaki $i^{9}\left(\mathrm{MAA}^{10}\right.$ : 1227.) y una katana de los siglos XVIII-XIX montada en katatemaki $^{11}$ (MAA: 665) con montura de tipo handachi ${ }^{12}$ y guarda inspirada

8 ALFARO FOURNIER, F.: Museos de armería de heráldica alavesa. Diputación Foral de Álava. Vitoria, 1983

9 Tipo de encordado de la empuñadura donde las tiras de tela (generalmente seda) se cruzan entre ellas sin llegar a retorcerse. Este tipo de encordado fue muy popular en los sables japoneses de tipo tachi de los siglos XIII a XV, y también en los posteriores modelos de sable uchigatana con montura de tipo handachi, o montura a imitación de los sables antiguos anteriormente mencionados. Pese al categoría cortesana de que solía gozar este encordado, es uno de los más sencillos y planos.

10 Número de inventario/ catalogación del Museo/ Armería de Álava. Utilizaremos MAA, para referirnos mediante siglas al Museo de Armería de Álava.

11 Encordado de la empuñadura o tsukamaki, donde las tiras de tejido se cruzan mientras se retuercen entre sí, salvo en la zona central de la empuñadura, que queda recubierta uniformemente. Esta superficie central está destinada al agarre con una única mano, traducción del término katate. Este tipo 
en una obra del artista Yoshiyuki Denryûsai Gizui, del círculo de la escuela Hamano ${ }^{13}$. El museo también cuenta con una katana de los siglos XVIII-XIX, con montura handachi, incluyendo una aoi $t s u b a^{14}$, y con una empuñadura trenzada en estilo tsumami maki ${ }^{15}$ (MAA: 1124). La colección de sables largos se completa con una katana del siglo XIX (MAA: 1125) con piezas de la empuñadura decoradas con motivos de langosta marina (ebi) y empuñadura trenzada con jabara itō o cordón muy fino entrecruzado en el estilo tsunami ya mencionado.

El museo también cuenta con una colección de tres sables cortos o wakizashi, ninguno firmado y todos datados en el siglo XIX. Uno de ellos cuenta con una empuñadura trenzada mediante el método de tsumami maki (MAA: 662), con fuchi-kashira (pomo-virola) del estilo de la provincia de Mino. Otro de los sables cortos, utiliza para su empuñadura el estilo hineri maki ${ }^{16}$ (MAA: 663). Esta pieza cuenta con una montura completa incluyendo el pequeño estilete (kozuka-kogatana) y una guarda o tsuba de la tipología namban ${ }^{17}$ de la provincia de Awa imitando una obra de la zona china de Kanton, con un diseño de un dragón incrustado mediante incrustaciones de plata (gin zōgan). También otro wakizash en koshirae (montura) de latón (MAA: 691). El wakizashi que completa la colección, cuenta

de encordado fue muy popular en el siglo XV, donde el agarre a una mano de los sables se volvió un práctica común entre los samuráis.

12 Handachi: Originalmente se trataba de un modelo híbrido entre un sable tachi (filo hacia abajo) y u uchigatana (filo hacia arriba). Este modelo handachi era preferentemente utilizado para ceremonias, siendo el motivo de su creación, la utilización de un mismo sable para dos tipos de vestimenta distinta, cuando en una de ellas la etiqueta exigía portar tachi, y en la otra uchigatana.

13 Hamano: Escuela de orfebres y artistas de monturas de sables fundada a principios del siglo XVII por Hamano Shōzui. Esta escuela continuó con cinco generaciones, que a su vez produjeron otras líneas y escuelas que llegaron a trabajar hasta mediados-finales del siglo XIX.

14 Aoi gata: Forma de tsuba o guardamanos, que recuerda la hoja de la malva. La superficie se compone de cuatro gallones con terminaciones conopiales. Muy habitual en los sables de tipo tachi o handachi.

15 Tipo de tsukamaki o encordado de la empuñadura, donde todas las tiras de tejido (itō) se retuercen entrecruzan entre sí, alternando los itō inferior y superior de cada uno de los cruces. Se trata de una de las formas de encordado más comunes, desde el siglo XVI hasta nuestros días.

16 Un tipo de tsukamaki que surgió a finales del siglo XVI a partir del anteriormente explicado tsumami maki, siendo practicamente identico a este ultimo salvo por el hecho de que cada uno de los ito se retuerce antes de cruzarse con el contrario, creando más volumen y textura en la empuñadura.

17 Las namban tsuba, son una tipología de guardas de sables japoneses originada en el siglo XVI en China y más tarde producidas en Siam (Tailandia), Ceilán (Sri Lanka) y las Islas Holandesas Orientales (Indonesia). Los motivos utilizados solían ser mascarones, leones y dragones, envueltos en un entramado de estilización vegetal que en Japón denominaron karakusa.

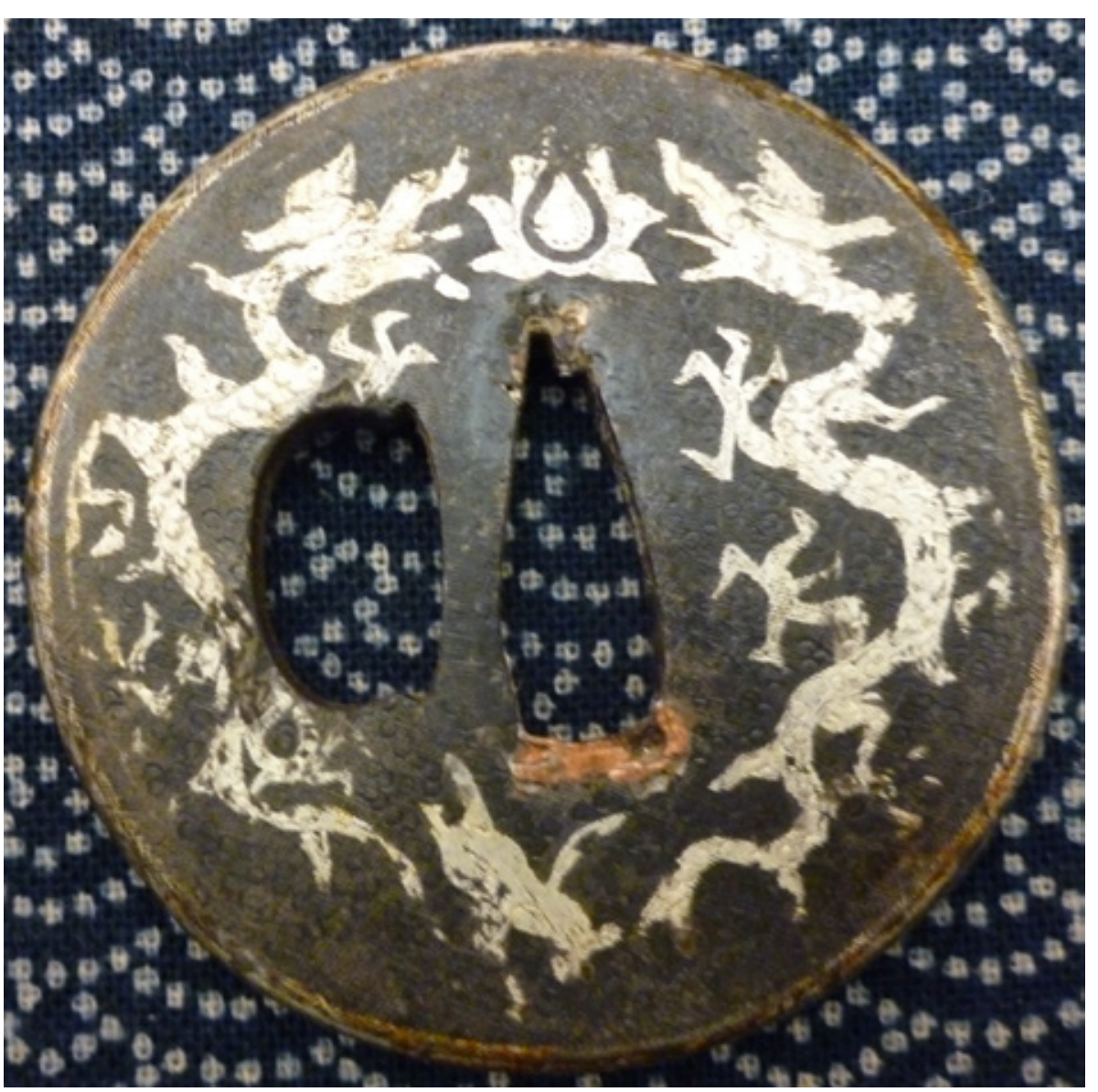

Fig.2: Guardamanos (tsuba) de tipo namban. Museo Armería de Álava, Vitoria-Gasteiz 
con un añadido (occidental) de cuero en la empuñadura, fijado con tachones. Este método se llevaba a cabo por anticuarios y coleccionistas occidentales de finales del siglo XIX y principios del siglo XX, cuando la empuñadura perdía su encordado. En aquella época podía ser harto complicado encontrar a un artista que rehiciera el tsukamaki, por lo que se optaba por esta versión anacrónica a fin de dar más presencia a la pieza (MAA: 661).

La última de las armas japonesas a la que nos vamos a referir es un puñal o tantô, sin firma, de estilo hamidashi ${ }^{18}$ y fechado en el siglo XIX. Tiene una montura metálica a imitación de las monturas de hueso tallado. Esta es una pieza única en nuestras colecciones y está considerada una rareza en el mundo del koshirae (montura) decimonónico de marfilhueso-metal (MAA: 1020).

Debido a los productos químicos que se han aplicado para su conservación (posiblemente Palaroid), las hojas presentan una capa amarillenta, siendo muy difícil apreciar los indicadores de calidad de forja. Durante la investigación previa a la elaboración de este artículo, se han podido desmontar la totalidad de los sables a excepción de un sable largo katana, dos sables cortos wakizashi y la totalidad de los puñales tantō, en algunos casos debido a las especiales características de la montura de la pieza, en otros debido a la acumulación de suciedad, productos químicos aplicados para la conservación y la falta de un desmontaje y limpieza habitual. Esto ha hecho que las labores de datación y atribución sean especialmente complicadas, debiendo remitirnos a los indicadores visibles para pode establecer una estimación de datos a la hora de realizar la redacción de esta investigación.

\section{LA COLECCIÓN DE TÔSÔGU $U^{19}$ DEL MUSEO DE BELLAS ARTES DE BILBAO - BILBOKO ARTE EDERREN MUSEOA}

Las donaciones llegaban al museo por varias vías, piezas sueltas o colecciones enteras, algunas de carácter testamentario y otras en vida del propio coleccionista. Dentro de este nutrido grupo de mecenas cabe destacar a: José Palacio, Laureano de Jado, Antonio Plasencia, Manuel Losada, o Mercedes Basabe, viuda de Manuel Taramona, entre otros. En

18 Tipo de montura de puñal o sable corto característica por contar con una tsuba o guarda de muy pequeñas dimensiones, poco más grande que la virola o fuchi.

19 Partes de la montura de los sables japoneses. el contexto de esta investigación, la figura de José Palacio es la que más nos interesa, no sólo por ser uno de los mayores coleccionistas, sino por ser el donante de la gran colección de arte oriental que hoy se exhibe en el museo. Dentro de su heterogénea colección hay cabida para todas las artes de Asia Oriental, destacando la presencia de Japón, siendo de especial interés para nosotros la enorme cantidad de obras de arte de armamento japonés. El contacto entre la institución y el coleccionista se inició durante la Guerra Civil, cuando el Departamento de Orden Público determinó que la colección de José Palacio debía permanecer en depósito en el Museo. En 1938, cuando su heredera María de Aretxbaleta retiró el depósito, decidió donar al Museo 6 tsuba, iniciándose así la colección de arte de armamento japonés en la institución pública. Tras la muerte de José Palacio, María de Aretxbaleta asumió el control de la colección ${ }^{20}$. En 1952 comenzaron las donaciones, siempre con la condición de que las piezas no se almacenaran en los fondos, sino que se crearán vitrinas ex profeso para exponer las piezas donadas. La directiva del Museo accedió a todas las peticiones y esto animó a que en el año siguiente las donaciones se incrementaran considerablemente. Finalmente, tras su muerte en 1954, el resto de la colección pasó a formar parte del Museo como legado testamentario. La colección José Palacio que donó María de Aretxbaleta se compone de 523 piezas de las cuales 291 son de arte de Extremo Oriente y 221 de origen japonés. Esto denota la clara preferencia que tenía el coleccionista hacia piezas de origen nipón.

Como todo buen coleccionista, los viajes a distintas zonas del globo terráqueo formaban parte de su rutina, sin embargo, la mayoría de las piezas extremo-oriental que componían su colección, las adquirió en subastas europeas. Al igual que otros coleccionistas españoles, como el XVII marqués de Cerralbo, el Hōtel Drouot y sus subastas jugó un papel primordial en la construcción de su colección ${ }^{21}$. Dentro del mundo de los coleccionistas de armamento japonés, José Palacio es uno de aquellos estudiosos que adquirían piezas en base a una documentación sobre las mismas sumado a un juicio crítico y estético. Dentro de la donación al museo de María Aretxbaleta, se encuentra la Biblioteca José Palacio, en la que encontramos libros como Les gardes de sabre japonais, de François Poncetton, una obra clave en los estudios occidentales de monturas de sables japoneses de principios-mediados del siglo XX. Este tipo de evidencias testimonian que José Palacio, más allá del componente exótico e histórico-antropológico que poseían las armas japonesas, las apreciaba en base a un

20 PEREDA, A. La colección palacio Arte japonés en el Museo de Bellas Artes de Bilbao [Catálogo de exposición.], Bilbao, Museo de Bellas Artes de Bilbao, 1998.

21 TABAR ANITUA, F.: Lujo asiático. Artes de Extremo Oriente y chinerías en el Museo Cerralbo. Fundación Museo Cerralbo. Ministerio de Cultura. Madrid, 2004. Pp. 34-35. 

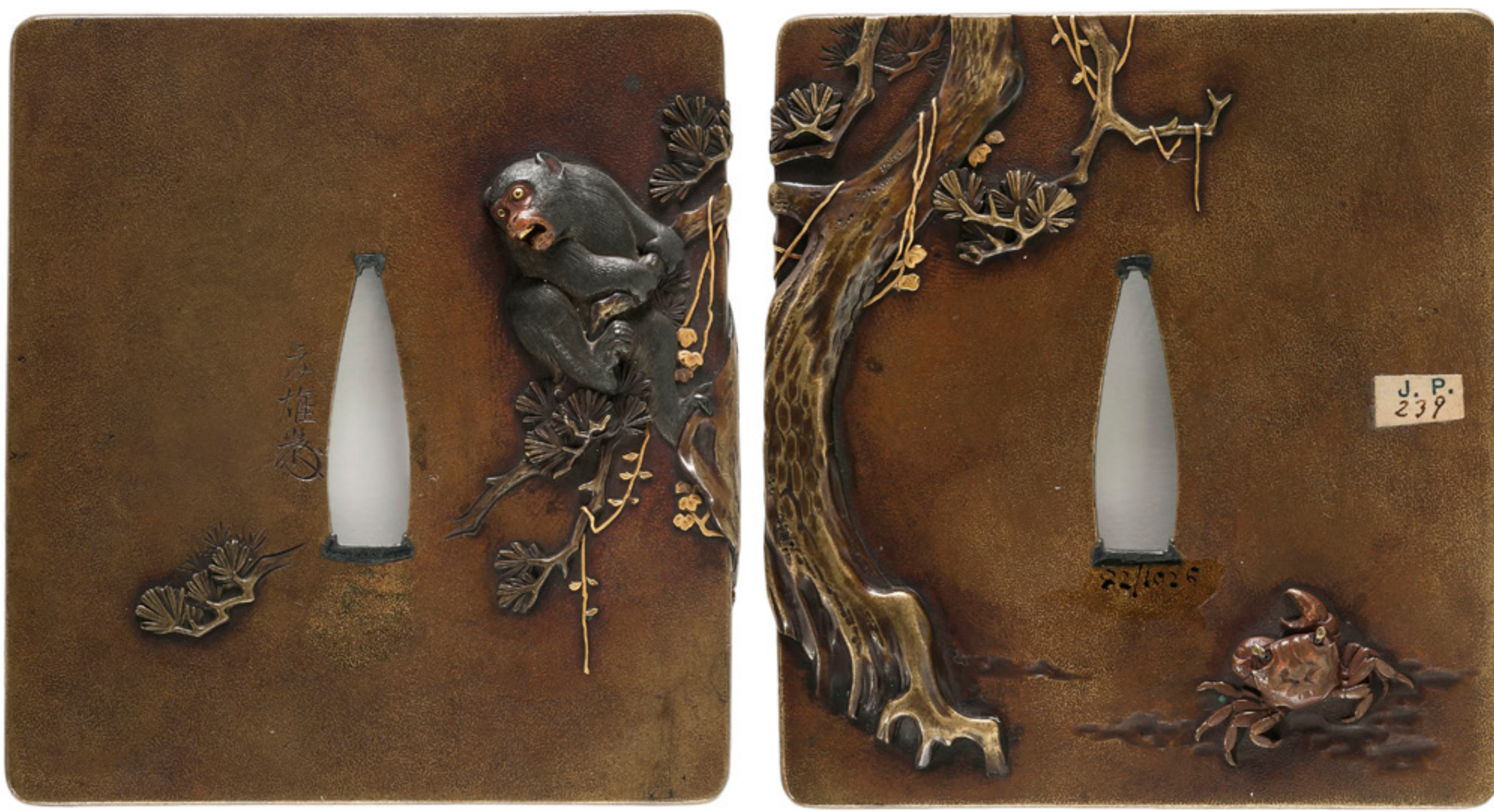

Fig. 3: Tsuba del artista Kanō Natsuo en el Museo de Bellas Artes de Bilbao 
juicio artístico. Gracias a esto, el conjunto de tōsōgu perteneciente a la Colección José Palacio del Museo de Bellas Artes de Bilbao está entre los más exquisitos del mundo. Numerosos especialistas han atestiguado esto, como Lawrence Smith, Conservador de Antigüedades del British Museum, que en 1984 visitó y estudió las piezas del museo, o el académico y coleccionista Federico Torralba, que en 1985 catalogó el conjunto de la colección oriental ${ }^{22}$.

La colección de tôsôgu, o partes de la montura de los sables japoneses, del Museo de Bellas Artes de Bilbao se compone de 38 guardamanos o tsuba, y dos empuñaduras de pequeños estiletes que se recogían en la vaina del sable, denominados kozuka. Especialmente en el campo de las guardas o tsuba, considerada la "reina" de todas las partes de la montura del sable japonés ${ }^{23}$, la colección del Museo de Bellas Artes de Bilbao es, sin duda, la de mayor variedad y calidad de todo el territorio español.

Las 38 piezas que componen la colección de tsuba del Museo de Bellas Artes de Bilbao, son obras de gran calidad que podemos datar entre los siglos XVII-XVIII-XIX, estando 15 firmadas por los artistas que las realizaron. De las tsuba con mei (firma) destacan las figuras de grandes artistas como: Kanō Natsuo ${ }^{24}\left(\mathrm{MB}^{25}:\right.$ 82/1026), Iwamoto Konkan ${ }^{26}$ (MB: 82/991) o Sugiura Jōi ${ }^{27}$ (MB: 82/400), Itō Masahisa ${ }^{28}$ (MB: 82/1002), Itō Masachika ${ }^{29}$ (MB: 82/992), Yanagawa Mitsutane ${ }^{30}$ (MB: 82/995), Yanagawa Naoharu ${ }^{31}$ (MB: 82/1053), Shigenobu

22 TORRALBA SORIANO, F.: Estudios sobre Arte Oriental. Colección Federico Torralba de Estudios de Asia Oriental. Prensas Universitarias de Zaragoza, 2008

23 HAYNES, R. E.: Random Glosses. Tsuba no Hanashi. Robert Haynes LTD. San Francisco, 1995. P.21.

24 Kanō Natsuo (1828-1898): Eminente artista y académico, considerado por muchos especialistas como "el último gran artista de tsuba del periodo Edo (1603-1868)".

25 Número de inventario / catalogación del Museo de Bellas Artes de Bilbao. Utilizaremos las siglas MB para referirnos al Museo de Bellas Artes de Bilbao.

26 Iwamoto Konkan (1744-1801): Calígrafo, poeta, pintor, y artista de tsuba sexta generación de la escuela Iwamoto. También se le conocía por los nombres: Kisaburō, Chōunsai, Hakuhōtei, Shunshodō y Nanpō.

27 Jōi Sugiura (1701-1761), artista de tsuba y tōsōgu, firmaba también sus obras como: Issan, Issandō Kōshinobu, Myōhō Kihen, Nagaharu, Nanryō Nanki, Sen’emon, Shiboku o Tashichi. Procedente de la ciudad de Kano en la provincia de Mino, estudió el estilo de la escuela Nara Toshinaga, siendo alumno directo del dirigente de esta línea de la escuela Nara. Sirvió para varios señores feudales y fundó su propio estilo, conocido como Jōi.

28 Masahisa Heihachirō Itō: Dos generaciones de artistas que trabajaron bajo el mismo nombre, desce mediados de siglo XVIII a principios del XIX, procedentes de la zona de Bushū y pertenecientes a la escuela Odawara - Itō.

29 Masachika Itōo: Artista de tsuba de la escuela Edo Itō en la línea Kitani. Nace en 1746 y estuvo activo hasta 1797. Firmaba como Masachika Bushū Jū, aunque su nombre era Tomizō.

30 Artista de tsuba de la escuela Yanagawa, activo durante el siglo XIX
Shōami ${ }^{32}$ (MB: 82/996), Takahashi Kinai ${ }^{33}$ (MB: 82/1004), Kunihiro ${ }^{34}$ (MB: 82/1042), Myōchin Munesuke ${ }^{35}$ (MB: 82/1054), Umetada Narishige ${ }^{36}$ (MB: 82/1067), Kaneie ${ }^{37}$ (MB: 82/1066) y Kitagawa Kaneishi ${ }^{38}$ (MB: 82/1069 y 82/1070). Del resto de piezas sin firma es fácil deducir su procedencia en función de su estilo, contando con tsuba de las escuelas namban (MB: 82/1028), Koike Yoshiro ${ }^{39}$ (MB: 82/989), Ōnin ${ }^{40}$ (MB: 82/1010), Kaga Yoshiro (MB: 82/988 y 82/1089), Hokori Yoshiro (MB: 82/997), Hamano (MB: 82/990), Saotome ${ }^{41}(\mathrm{MB}$ : 82/1035), Jakushi Koremitsu ${ }^{42}$ (MB: 82/1072) y Takafusa Kajikawa ${ }^{43}$ (MB: 82/1079).

31 Naoharu Yanagawa: Artista de tsuba nacido en 1750 en la ciudad de Edo, como tercera generación de la escuela Yanagawa, también conocido por los nombres Benzō, Koheji, Niryūan, Onkokan, Onkotei, Sanzaemon y Seiunsha. Estableció su taller en el barrio de Kanda de Edo (Tokio).

32 Shigenobu Shōami: Artista de tsuba activo en el área de Yamashiro entre 1675-1700. El nombre de nacimiento del tercer miembro de la familia (sandaime) era Jirōhachi.

33 Segunda generación de artistas de la escuela Takahashi Kinai, también llamado Ōhashi Tajūro, activo entre finales del siglo XVII y principios del XVIII

34 Kunihiro: Escuela de forja formada por un grupo de cuatro artistas de la zona de Bushū que trabajaron durante el periodo Edo (1603-1868) entre el 1700-1800. También realizaron tsuba y partes de la montura del sable japonés.

35 Myōchin Munesuke: Artista de tsuba perteneciente a la escuela Myōchin que trabajó en la escuela Fujiwara para la familia Ki en la ciudad de Edo. También se le llamaba Shikibu y se conocen obras suyas entre 1800-1825.

36 Kajiemon Umetada: Diversos artistas del periodo Edo entre el 1700 y el 1800 utilizaron este nombre para firmar sus piezas. Entre ellos encontramos a Narikado, Naritsura, Narikata y Naritsugu.

37 Kaneie: Grupo de artistas de tsuba activos entre el 1450 y 1600 en la zona de Yamashiro. Se conocen dos firmas, la más antigua: Josshū Fushimi jū Kaneie, activo durante el siglo XV y XVI y Yamashiro Kuni Fuchimi Jü Kaneie de nombre propio Aoki, activo desde mediados a finales del siglo XVI.

38 Kanenori Nomura (Hikone/Ōmi): Estudiante de la Sōten Kitagawa, activo entre 1715-1750, también firmó bajo los nombres de Kaneishi, Saburōbei, Saburōii y Chūji. En sus primeros años siguió las formas barrocas y de temática de batallas característica de la escuela Sōten, más tarde comenzó a desarrollar su propio estilo.

39 El nombre Yoshirō que identifica a estas escuelas de las zonas de Kaga y Bizen proviene del nombre del sabe más populares de esta escuela era el mon sukashi o vaciado en forma de blasones familiares, decorados con incrustaciones de oro y shinchī (aleación de cobre, plomo y zinc).

40 Esta escuela debe su nombre a la era Ōnin (1407-1468), momento en el que se inició, perdurando la producción de sus piezas hasta la era Tenbun (1532-1554). Más que una única escuela o familia, se trata de un grupo de estilos de factura de tsuba.

41 Saotome: Familia de fabricantes de armaduras de la que surgieron escuelas de artistas de tsuba de gran fama. Tanto unas como otras, adquirieron especial fama durante el periodo Edo (1603-1868).

42 Sexta generación de la escuela de artistas de tsuba, Jakushi (Koremitsu), también llamado Nagami Unosuke, Ryūunken y Fūyōshi. Trabajó a mediados del siglo XIX.

43 Takafusa Kajikawa: Artista de laca japonesa urushi activo durante la primera mitad del siglo XIX. Pese a que la mayoría de sus obras son pequeños recipientes para guardar sellos o medicamentos llamados 

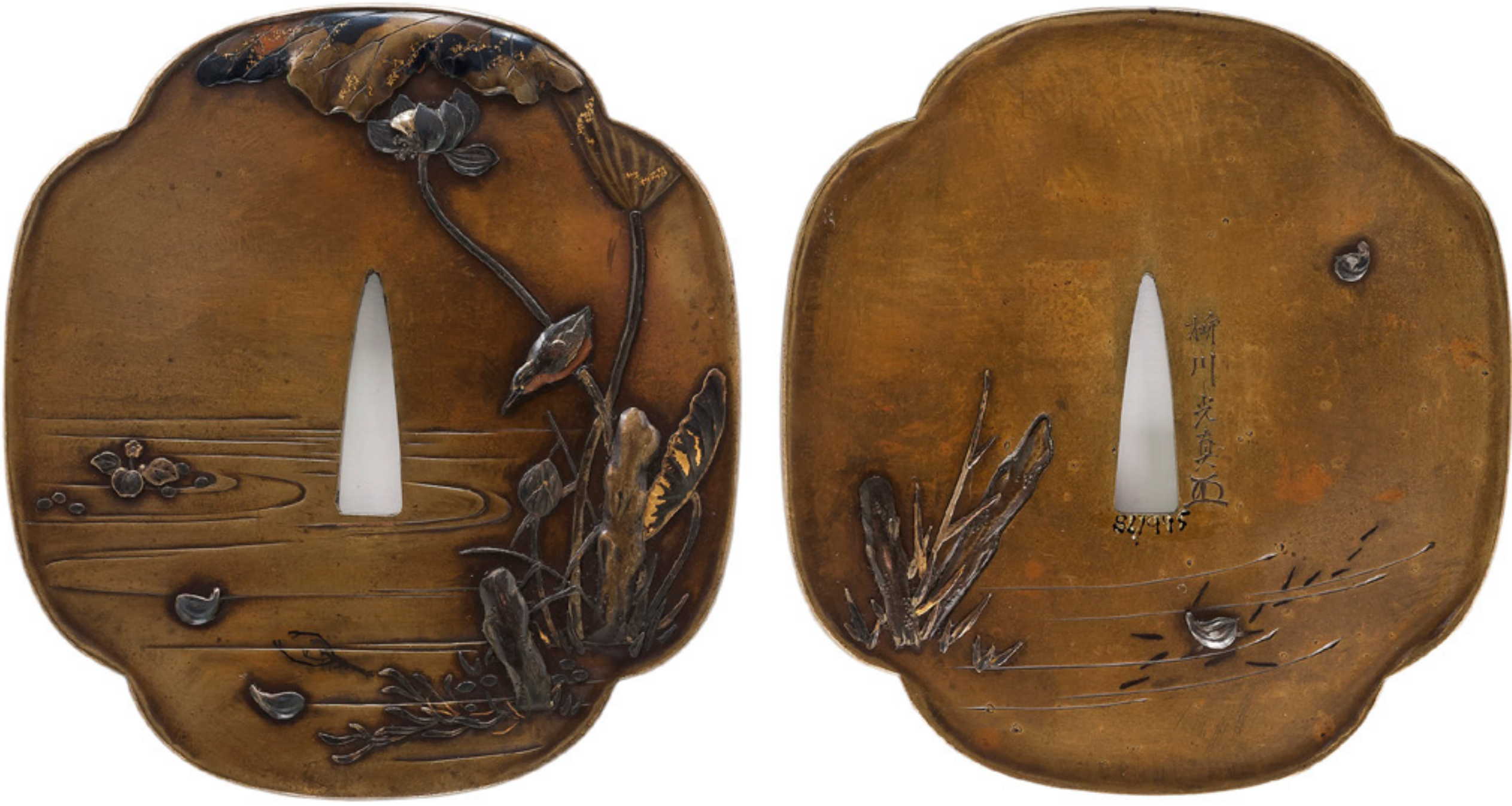

Fig. 4: Tsuba del artista Yanagawa Mitsutane en el Museo de Bellas Artes de Bilbao 
La colección se completa con dos kozuka o empuñaduras de pequeños estiletes. Una de ellas está firmada por el orfebre (kinkō) Motozane $^{44}$ (MB: 82/1041) del siglo XVIII y la otra es una pieza anónima del siglo XIX.

La catalogación de las piezas del Museo de Bellas Artes de Bilbao ha sido, con diferencia, la más sencilla de las llevadas a cabo para este estudio en el campo del armamento japonés. El motivo es que este museo se ha preocupado por realizar un análisis minucioso de cada una de sus piezas, tomando medidas y pesajes. Además, las tsuba y demás piezas del tōsōgu han sido analizadas mediante escáneres espectrales por científicos de la Universidad de Navarra siendo esta una iniciativa pionera no sólo a nivel nacional, sino también internacional en muchos casos. Con ello han sido capaces de determinar las aleaciones de cada una de las tsuba así como los porcentajes, en el caso de tratarse de compuestos mixtos. Más allá de los análisis geoquímicos, el Museo de Bellas Artes de Bilbao es la única institución española que se ha preocupado de las monturas de sables japoneses como parte del patrimonio histórico artístico japonés, más allá de su función como montura de un arma. En este sentido, podemos observar en su catálogo no sólo una descripción pormenorizada de cada tsuba, sino que también en muchos casos, se aportan lecturas de las firmas y posibles atribuciones a escuelas de artistas de tsuba. En nuestro estudio e investigación, hemos completado la información de la que disponían, mediante el estudio de cada pieza y la medición de partes que al ojo profano pueden no ser significativas, pero que en muchos casos suponen los indicadores que llaman a otorgar la autoría a una escuela o la datación a un periodo histórico. Además, hemos repasado la traducción de las firmas, actualizando las atribuciones con los datos de las últimas publicaciones científicas del ramo, llegando a datar e identificar piezas que ni siquiera cuentan con firma.

inrō y otras piezas trabajadas con laca japonesa tratada con oro (makie), también realizó algunas piezas de la montura del sable japonés, como tsuba y kozuka.

44 Motozane Sekijōken (1741-1830): Artista de monturas de sables, segunda generación de la escuela Ōyama, fundador de la escuela Taizan Sekijōken. Estudió las escuelas Nara, Hamano, Yokoya y Sugiura y más tarde fundó su estilo en Mito, Hitachi. También fue conocido por los nombres Jihei, Motoharu, Shinemon, Taizanken y Tōgu.

\section{LOS DOS SABLES JAPONESES DEL MUSEO SAN TELMO (DONOSTIA SAN SEBASTIÁN) EN GORDAILUA, CENTRO DE COLECCIONES PATRIMONIALES DE GIPUZKOA EN IRUN}

Este museo cuenta con dos piezas, sin embargo, ninguna se encuentra en el Museo San Telmo de Donostia-San Sebastián, sino en Gordailua, Centro de Colecciones Patrimoniales de Gipuzkoa en Irun, que actúa de almacén para piezas de este y otros museos, así como centro cultural y museístico de exposiciones temporales e itinerantes.

Las dos piezas figuran como donación del General de Brigada, Vuecencia Prudencio Arnao y Basurto (1842-1902). Lejos de ser un coleccionista decimonónico, la vida de Prudencio Arnao se resume y rastrea mediante su distinguida carrera militar, tal y como muestran las condecoraciones recibidas tales como: Cruz Laureada de San Fernando de Segunda Clase, Cruz de la Real Militar Orden de San Hermenegildo, Medalla de la Guerra de África y cuatro cruces rojas al mérito militar. A los 17 años se alistó en el ejército y al poco partió a África, donde entre otras, participó en la batalla de Wad-Ras de 1860. Por todo ello, el caso de Vuecencia Prudencio Arnao se antoja como una excepción dentro de los mandos del ejército de tierra, puesto que el grueso de armamento japonés donado por militares a colecciones españolas, se vinculan más con la marina. Sin embargo, en 1860 Víctor Balaguer ${ }^{45}$ publica el tomo segundo de: Jornadas de Gloria o Los Españoles en África, donde se menciona a Prudencio Arnao. Es por tanto, posible que ambos se conocieran y que Balaguer plantara en Arnao la semilla de la curiosidad por las tierras lejanas que tanto le atraían. Pese a no haber encontrado documentos que atestigüen una posible amistad entre ambos, no hay que descartar que crearan lazos y que estos se extendieran en el tiempo, cuando Balaguer empezó a recibir sables procedentes de Japón e incorporarlos a su colección particular, que más tarde se transformaría en el Museo-Biblioteca Víctor Balaguer, que hoy en día exhibe varias armas japonesas en la localidad barcelonesa de Vilanova i la Geltrú.

La primera de las piezas que encontramos en el museo, es al mismo tiempo, la de mejor calidad. Se trata de un sable largo o katana, firmada por Kōzuke Daijō Fujiwara Sukesada ${ }^{46}$ (1633-1721), con montura de los siglos XVIII-XIX (MST ${ }^{47}$ : H-00 510). Tras examinar

45 Víctor Balaguer i Cirera (1824-1901) fue un político, escritor y periodista catalán de la Reinaixenca, a quien debemos el Museo-Biblioteca Víctor Balaguer en Vilanova i la Geltrú en Barcelona. En dicho museo, se conservan numerosas armas japonesas que tanto Balaguer como sus socios compraron en anticuarios de Europa y Asia Oriental.

46 Sukesada Bizen Osafune: Forjador de la escuela Bizen Osafune, estudiante de Hikobei no Jō Sukesada 


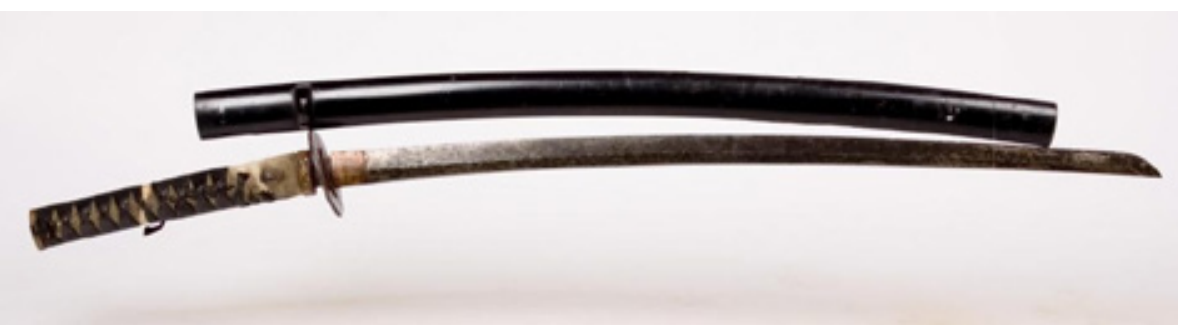

Fig. 5: Sable japonés del artista Kōzuke Daijō Fujiwara Sukesada del Museo San Telmo de Donostia-San Sebastián en Gordailua, Centro de Colecciones Patrimoniales de Gipuzkoa en Irun

brevemente la katana, se hizo patente que el nakago o espiga de la hoja, estaba firmado. Para comprobar si existe firma, generalmente es necesario desmontar la pieza, pero en este caso la espiga de la hoja sobresalía de la empuñadura por su parte superior, distinguiéndose una firma. Lo que debió ocurrir es que la empuñadura fue desmontada y posteriormente montada incorrectamente, lo que dejaba al descubierto, en la parte superior de la tsuka, un fragmento de la espiga metálica o nakago, en el cual podía entreverse un kanji o ideograma, indicando que la hoja estaba firmada. Debido a que el montaje de la empuñadura se había hecho mediante un remache doble de metal en lugar del tradicional mekugi o pasador de bambú, no era posible desmontar la pieza. Ante este descubrimiento, se llamó a los conservadores y restauradores del museo, para plantearles una intervención directa y mecánica sobre la pieza. La propuesta era utilizar una sierra radial y otros elementos para cortar los remaches y así liberar la empuñadura. Se expuso ante los conservadores y restauradores que tal cual se encontraba la katana era imposible determinar quién la forjó, así como a que siglo y escuela pertenece, pero si se consiguiera visualizar la espiga, el proceso sería inmediato. En la disertación a favor del informe de actuación, se dejó patente que el remache metálico ha sido una adición posterior no japonesa y que, lejos de proteger la pieza imposibilita su correcto estudio y supone un elemento anacrónico totalmente innecesario. Los responsables del museo valoraron los pros y los contras y finalmente decidieron llevar la pieza a los talleres, donde tras 30 minutos limaron, cortaron y retiraron los remaches

y activo a mediados del siglo XVI

47 Número de inventario / catalogación del Museo San Telmo de Donostia-San Sebastián en Gordailua Centro de Colecciones Patrimoniales de Gipuzkoa en Irun. Utilizaremos las siglas MST para referirnos a este museo.

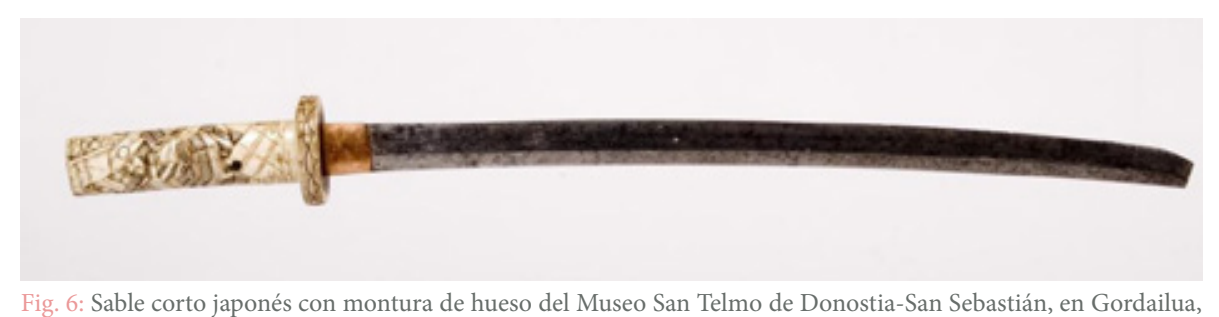
Centro de Colecciones Patrimoniales de Gipuzkoa en Iru

metálicos. Gracias a esto pudimos determinar la autoría de la pieza y datarla, presentándola inéditamente en esta publicación. Todos los miembros de la comunidad científica dedicada al estudio del armamento japonés debemos aplaudir enérgicamente la decisión y actuación del personal del museo que me atendió, por tomar esta iniciativa, atrevida en marcos de la geografía española, aunque totalmente lógica en términos internacionales y japoneses. Lamentablemente, en 1997, la hoja fue tratada con el ya conocido producto Palaroid, por lo que no se puede apreciar ningún detalle de grano (hada) o temple (hamon)

La segunda arma japonesa que atesora el museo es un sable corto o wakizashi. Se trata de una pieza con montura de hueso tallado (MST: H-00 510), una pieza típica de los suvenires que se exportaban desde Asia Oriental hacia Occidente, desde mediados del siglo XIX a principios del XX. Estas piezas generalmente estaban realizadas con huesos de reses o cuernos de caza mayor, en una factura generalmente muy pobre, siendo en la mayoría de los casos, piezas que realizaban mano de obra inmigrante en territorio japonés, o directamente producidas en Filipinas o China a imitación de piezas japonesas. La hoja, generalmente era de mala calidad, producida en serie cortando la plancha de metal en lugar de forjarla, ostentando el mismo valor de suvenir que la montura. Muchos coleccionistas no iniciados, caían en el error de creer estar comprando piezas de marfil, cuando en realidad se trataba de hueso. En este punto es importante esclarecer la diferencia, no sólo monetaria, sino cualitativa y artística de ambos materiales, pudiendo comprobar su origen fácilmente si se observan los característicos signos de porosidad del hueso, que el marfil carece ${ }^{48}$.

48 CABAÑAS MORENO, P.: Marfiles japoneses en las colecciones españolas. Tesis Doctoral. Universidad Complutense de Madrid. Madrid, 1993. P. 502. 
La decoración del sable corto del museo, concuerda con el de este tipo de piezas fabricadas en serie, plasmando imágenes bucólicas de samurái o cortesanos, vendiendo la imagen romántica que buscaban los "nuevos" fascinados por el exotismo nipón. En las colecciones españolas, el 90\% de las piezas adquiridas entre finales del siglo XIX y principios del XX como "sables japoneses con montura de marfil" eran este tipo de piezas de hueso ${ }^{49}$. A pesar que este wakizashi carezca de valor artístico, supone un interesante objeto que nos habla de la historia del coleccionismo occidental de piezas japonesas de finales del siglo XIX Y principios del XX. Además, cuenta con el valor anecdótico de ser uno de los primeros suvenires que los japoneses vendieron a los viajeros occidentales.

\section{RESULTADOS Y CONCLUSIONES}

Afirmamos que hemos alcanzado plenamente el objetivo principal de esta investigación. Como primera gran conclusión podemos decir que ahora valoramos con más acierto y precisión una parte de nuestro patrimonio, que nos invita a preservarlo con mayor tesón, gracias a la investigación realizada. Localizar este tipo de piezas relacionadas con la metalistería japonesa, estudiarlas, desmontarlas en algunos casos por primera vez, ya que no había habido hasta el momento un especialista que pudiera hacerlo, y catalogarlas es la gran aportación del trabajo presentado.

Concluimos que las colecciones vascas (y por extensión las del resto del territorio español) distan mucho de ser homogéneas. En las colecciones públicas podemos ver como conviven piezas de una gran calidad artística, firmadas por notables escuelas, con otras obras anónimas de grado medio, con armas y monturas de muy baja calidad, e incluso con suvenires para turistas.

Otra de las conclusiones extraídas al visitar las diferentes instituciones que albergan piezas referentes a armamento japonés, es que son necesarios un mayor número de especialistas, sobre todo lo que engloba al mundo del nihontō o sable japonés. El preocupante estado de conservación en el que se encuentran muchas de las piezas estudiadas, alertan sobre el futuro incierto del armamento japonés que forma parte de nuestro patrimonio artístico nacional.
Una gran mayoría de las obras precisan de una restauración, realizada por especialistas en la materia, para poder recobrar el brillo y grandeza de la que gozaban antaño. Pero más allá de cuestiones de restauración, el suceso más alarmante es el deficiente estado de conservación de algunas de estas piezas, fruto de un tratamiento erróneo del nihontō y sus partes. Es por esto que son necesarios conservadores especialistas, ya no para que elaboren catálogos y cartelas razonadas sobre las piezas, sino sobre todo para que eviten el deterioro progresivo que están sufriendo, y que provocará, en varios años vista, que perdamos por completo estas obras de arte. 


\section{BIBLIOGRAFÍA}

ALFARO FOURNIER, F.: Museos de armería de heráldica alavesa. Diputación Foral de Álava. Vitoria, 1983.

BUCK, T.: The art of Tsukamaki, Lloyd \& Tutle publishing limited, Polonia, 2014

FUKUSHI, S.: Tosogu classroom. [Vol. 1]. Traducido y publicado por SESKO, M. en colaboración con NBTHK AB [Nihon Bijutsu Tōken Hozon Kyōkai American Branch] y NBTHK EB [Nihon Bijutsu Tōken Hozon Kyōkai European Branch]. Lulu Inc. 2016.

FUKUSHI, S.: Tosogu classroom. [Vol. 2]. Traducido y publicado por SESKO, M. en colaboración con NBTHK AB [Nihon Bijutsu Tōken Hozon Kyōkai American Branch] y NBTHK EB [Nihon Bijutsu Tōken Hozon Kyōkai European Branch]. Lulu Inc. 2017.

GARCÍA GUTIÉRREZ, F. (com.): Arte Japonés y Japonismo [Catálogo de exposición.] Bilbao, Museo de Bellas Artes de Bilbao, 2014.

GARCÍA GUTIÉRREZ, F: "Tsuba: un signo distintivo de los caballeros de Japón: colección de "tsuba" en el Museo de Bellas Artes de Bilbao", Buletina / Boletín / Bulletin del Museo de Bellas Artes de Bilbao del Museo de Bellas Artes de Bilbao, no. 3, 2007, pp. 101-159.

HAYNES, R. E.: Random Glosses. Tsuba no Hanashi. Robert Haynes LTD. San Francisco, 1995.

HAYNES, R.E.: The Index of Japanese Sword Fittings and Associated Artists. Vol. I-II-III. Nihon Art Publishers, EEUU, 2001.

HAYNES, R.E.: The Index of Japanese Sword Fittings and Associated Artists. (Corrigenda) Nihon Art Publishers, 2011.

HAYNES, R.E.: The Index of Japanese Sword Fittings and Associated Artists. (Corrigenda) Nihon Art Publishers, EEUU, 2015.

LISSENDEN, J.: The Nanban Group of Japanesse Sword Guards: A Reppraisal. Double Dragon Publishing, Durham-Ontario, (Canada), 2006.
MASSEY, D. / WADA, T.: Aizu and Aizu Shoami Tsuba, Nihontocraft Ed, Louisville. Kentucky, EEUU, 2006.

MURAKAMI, K. / SESKO, M.: Choshu no tsuba. Tokio, 1973. Reprint by Lulu Inc. 2016.

OGAWA, M.: Art of the samurai. Japanese arms and armor 1156-1868. The Metropolitan Museum of Art. New York, EEUU, 2009.

PEREDA, A.: La colección palacio. Arte japonés en el Museo de Bellas Artes de Bilbao [Catálogo de exposición.], Bilbao, Museo de Bellas Artes de Bilbao, 1998.

CABAÑAS MORENO, P.: Marfiles japoneses en las colecciones españolas. Universidad Complutense de Madrid. Madrid, 1993.

SAGASTE, D.: "La gestión de las colecciones de arte asiático en los museos españoles: el caso de la Colección Palacio en el Museo de Bellas Arte de Bilbao", en VV. AA.: Actas del I Foro de Investigación de Asia del Pacífico. Granada, Universidad de Granada-Casa de Asia 2006, pp. 455-472.

SALA IVARS, M. A.: "Francisco López López, coleccionista y erudito del sable japonés": El Sable Japonés: Manual de Coleccionista. LÓPEZ, F.; ELIZONDO, M.J. Editorial Alas. Barcelona, 2016, pp.11-15.

SALA IVARS, M. A.: "Los sables japoneses y sus complementos: objetos de deseo de nuestros coleccionistas/compradores”. Revista de Museología. № 65. Colecciones Asiáticas en España, Madrid, 2016, pp. 54-66.

SALA IVARS, M. A.: "Meiji: Revolución y renovación en las artes del tôsôgu", en Meiji. El nacimiento del Japón universal. Universidad de Cádiz, 2019, pp. 43-56.

SALA IVARS, M. A.: Tōsōgu: Lugares en el metal. Monturas de sables japoneses en colecciones españolas. Tesis doctoral. E-prints UCM. Madrid, 2018.

SESKO, M.: Genealogies and schools of Japanese swordsmiths. Herstellung ung Vellag. Books on Demand, Norderstedt, Alemania, 2010. 
SESKO, M.: Genealogies of Japanese tsuba and tōsō-kinkō artists, Herstellung ung Vellag. Books on Demand, Norderstedt. Alemania, 2011.

SESKO, M.: Handbook of Sword Fittings related terms, Books on Demand, Norderstedt, Alemania, 2011.

SESKO, M.: Identifying Japanese seal script. Lulu Inc. 2014.

SESKO, M.: Signatures of Japanese Sword Fitting Artists. Lulu Inc. 2014.

SESKO, M.: Swordsmiths of Japan. Lulu Inc. 2015

SESKO, M.: The Japanese toso-kinko schools. Lulu Inc. 2012.

TABAR ANITUA, F.: Lujo asiático. Artes de Extremo Oriente y chinerías en el Museo Cerralbo. Fundación Museo Cerralbo. Ministerio de Cultura. Madrid, 2004.

TORRALBA SORIANO, F.: Estudios sobre Arte Oriental. Colección Federico Torralba de Estudios de Asia Oriental. Prensas Universitarias de Zaragoza, 2008.

VV.AA.: Museo Provincial del Álava. Diputación Foral de Álava. Consejo de Cultura. Vitoria, 1967.

VV.AA.: San Telmo. Crónica de un centenario. San Telmo Museoa Ed. Donostia-San Sebastián, 2002.

VV.AA.: STM, Museo sobre la sociedad vasca. San Telmo Museoa Ed. Donostia-San Sebastián, 2016. 